\title{
Em Prol do Realismo Científico no Ensino
}

\section{For the Sake of Scientific Realism in Teaching}

Luiz Henrique Martins Arthury¹

João Otavio Garcia²

\begin{abstract}
'Instituto Federal de Educação, Ciência e Tecnologia de Santa Catarina (IFSC), Jaraguá do Sul, SC, Brasil. Autor correspondente: luiz.arthury@ifsc.edu.br

${ }^{2}$ Universidade Federal de Santa Catarina (UFSC), Florianópolis, SC, Brasil.
\end{abstract}

Resumo: Diante de exemplos atuais de atitudes anticientíficas com resultados perniciosos à saúde pública, buscamos problematizar o ensino de ciências em moldes sociologistas que, embora enfatizem aspectos relevantes da atividade científica, são limitados e enviesados. Ilustrando alguns episódios do desenvolvimento da ciência que atestam uma franca correlação entre as teorias científicas e uma realidade subjacente, procuramos enfrentar algumas aproximações típicas do pensamento relativista para chamar a atenção para aspectos da objetividade científica pouco abordados no ensino de ciências. Objetivamos, com isso, contribuir com a prática docente dos professores interessados em questões sobre a objetividade científica e os usos e abusos que se faz dos preceitos científicos em contextos duvidosos, para que complementem sua própria posição a respeito.

Palavras-chave: Eduação científica; Realismo científico; Objetividade científica; Relativismo; Pseudiciência.

\begin{abstract}
In face of current examples of unscientific attitudes with detrimental results to public health, we seek to problematize the teaching of sciences in a sociological way that, while emphasizing relevant aspects of scientific activity, are limited and biased. Illustrating some episodes of the development of science that attest to a frank correlation between scientific theories and an underlying reality, we try to address some typical approximations of relativistic thinking to draw attention to aspects of scientific objectivity that are not addressed in science education. We aim, therefore, to contribute to the teaching practice of teachers interested in questions about scientific objectivity and the uses and abuses of scientific precepts in dubious contexts, so that they complement their own position in this respect.
\end{abstract}

Keywords: Scientific education; Scientific realism; Scientific objectivity; Relativism; Pseudoscience. 


\section{Introdução}

Dada sua onipresença em nosso meio de vida, e por representar uma maneira exitosa de entender o mundo que nos cerca, a atividade científica desperta não apenas o interesse de muitas pessoas, mas também o interesse de pensadores desejosos em entender seu funcionamento e/ou criticar suas condutas e exageros. Justamente por determinar tão profundamente nossa sociedade, a ciência é foco de incontáveis abordagens ao longo da formação escolar, em todos os níveis. Seja para detratá-la ou defendê-la, muito professores, se não todos, têm sua relação pessoal com esse campo e a traz em sua prática docente, sendo ou não das áreas das ciências naturais.

Mas assim como, segundo a máxima, tudo é prego para quem tem um martelo nas mãos, cada profissional tende a enxergar a ciência com um viés epistemológico, ainda que de modo inconsciente. Dentre esses vieses, alguns bastante inadequados como os categorizados por Fernández et al. (2002), que constatam que mesmo professores de ciências podem apresentar visões distorcidas sobre a atividade científica, como as visões empíricoindutivista, rígida e cumulativa, possivelmente decorrente da falta de reflexão crítica e de um ensino que se limita a uma simples transmissão dos resultados da ciência. Não é descabido, portanto, pensar que seus alunos estejam sendo instruídos com essas visões, o que por si já é fonte de preocupação acadêmica de pesquisadores da área de ensino de ciências. $E$ se professores de ciências, que possuem uma formação que os aproxima dos conteúdos científicos trabalhados na escola, podem apresentar essas visões distorcidas, imaginamos que entre os profissionais de outras áreas o problema é mais grave.

Neste trabalho pretendemos chamar atenção para um viés que consideramos pernicioso à formação dos estudantes, ao mesmo tempo em que tem se tornado comum no meio escolar. Se de um lado há exageros em relação a visões empiristas ou mesmo cientificistas, por outro há também exageros por parte de quem visa diminuir a objetividade da atividade científica e resumi-la a um conjunto de arbitrariedades socialmente construídas. De nossa parte, não pretendemos nos colocar nas extremidades deste espectro, mas chamar atenção para a possibilidade de que esta balança possa estar, talvez, desequilibrada para o lado relativista, em alguns contextos.

\section{Relativizando}

Um dos epistemólogos frequentemente lembrados quando se pretende enfatizar o caráter social do desenvolvimento científico é Thomas Kuhn. Claramente influenciado por Ludwik Fleck, um dos primeiros pensadores a chamar atenção para os aspectos sociais da instituição científica (DELIZOICOV et al., 2002), Kuhn foi bem-sucedido em caracterizar a ciência sob seus aspectos de produção social do conhecimento. Para tanto, enfatizou como o cientista atua em um meio com paradigmas colocados e que definem a agenda daquele. Isso se reflete, segundo ele, até mesmo no modo como o cientista é iniciado na academia, onde a educação "[...] semeia o que a comunidade científica, com dificuldade, alcançou até aí - uma adesão profunda a uma maneira particular de ver o mundo e praticar ciência" (KUHN, 1979, p. 55). Isso certamente possibilita o tipo de visão que atribui ao cientista uma posição de simples integrante de uma força coletiva maior, que determinaria, por razões essencialmente históricas e sociológicas, o tipo de conhecimento que é produzido. Esse conhecimento, por sua vez, seria apenas consensual e contingencial, sujeito a ser substituído a qualquer momento. 
Naturalmente concordarmos que ciência se faz em uma época, em um contexto, mas não endossamos que esses estejam associados a um conhecimento meramente contingencial, pragmaticamente arbitrário e que acabará por ser substituído por outro (visão típica do relativismo epistemológico). Não que esses aspectos não existam, pelo contrário, pensamos que o conhecimento científico é conhecimento, sobretudo, humano. $\mathrm{O}$ que nos incomoda são as exegeses que insistem nesses aspectos enquanto únicos determinantes do fazer científico. Que não citam os progressos ocasionados também por iniciativa singular humana, do cientista que, à revelia dos padrões supostamente impostos pela comunidade científica, aventa ideias criativas e passíveis de testes com alta correlação empírica. Mesmo Kuhn, enfatizando a influência indelével da comunidade no trabalho do cientista, sugeriu que:

Embora a investigação susceptível de ter êxito requeira uma adesão profunda [do cientista] ao status quo, a inovação continua a ocupar uma posição central. Os cientistas são treinados para funcionar como solucionadores de quebra-cabeças dentro de regras estabelecidas, mas são também ensinados a considerar-se eles próprios como exploradores e inventores que não conhecem outras regras além das ditadas pela natureza (KUHN, 1979, p. 78).

Reproduzimos e grifamos essa última frase: "[...] mas são também ensinados a considerar-se eles próprios como exploradores e inventores que não conhecem outras regras além das ditadas pela natureza" (KUHN, 1979, p. 78). Gostaríamos que essa colocação fosse mais conhecida, para não ficarmos exclusivamente sujeitos aos profissionais que trazem Kuhn apenas para insistir na determinação social do conhecimento científico, com a consequência sugestiva enviesada de que os conhecimentos produzidos nesse contexto são arbitrários e intrinsecamente relativos. A citação acima sugere que Thomas Kuhn, ele próprio um doutor em física, conhecia a importância do papel criativo que o cientista exerce em sua prática, cuja coletividade, certamente influenciadora de seu trabalho, é também resultado dessa posição individual relativa à natureza.

Por exemplo, é claro que Einstein estava sujeito aos paradigmas da física do final do século 19, o que certamente influenciou o seu trabalho, mas sua visão pessoal somada ao seu interesse por áreas de fronteira entre grandes campos da física, como a mecânica, termodinâmica e eletromagnetismo (RENN, 2004), o levaram por caminhos bastante originais de pensamento. Em suma,

Do surgimento da teoria da relatividade especial pode-se vislumbrar um exemplo de como [mudanças conceituais] se concretizam como resultado da interação entre o conhecimento disponível da física de então com o ponto de vista individual de um pesquisador (RENN, 2004, p. 30).

Nem tanto ao mar, nem tanto à terra, diz o conhecido provérbio. Nem tanto à coletividade encabrestadora, nem tanto à individualidade criadora, dizemos. Coletividades são importantes e indivíduos são importantes.

Sobre a substituição de uma teoria científica por outra, o que pode ser visto como tudo pode estar errado (alegação que provavelmente os colegas já ouviram), consideramos relevante o que se segue. Mesmo em supostas rupturas (ou revoluções científicas), não se observa uma descontinuidade patente entre velhas e novas teorias, pelo menos não do modo 
peremptório com que alguns pensadores caracterizam a evolução essencialmente descontínua da atividade científica, como Kuhn (1970) e Feyerabend (1977) (ou, talvez mais corretamente, autores que seguem por caminhos mais fundamentalistas entre as ideias dos epistemólogos supracitados). Claro que não pretendemos com isso passar uma imagem de ciência que progride de modo cumulativo e linear, o que seria ir de um extremo a outro. Apenas gostaríamos de chamar atenção para que, apesar de a incomensurabilidade kuhniana ou feyerabendiana poder ser vista (com ressalvas) ${ }^{1}$ em um ou outro conceito ou grandeza, de modo geral a ciência também se erige nas ruínas de suas destruições. Essa dinâmica pode ser vista.

[...] como um processo copernicano, pois processos de ruptura conceitual se completam de maneira semelhante à revolução de Copérnico, que também criou um novo sistema de mundo a partir da colocação, no centro, de uma estrela antes periférica, o Sol, mas que para isto fez uso do complexo maquinário da astronomia já então desenvolvido ao invés de iniciar por uma tábula rasa. (RENN, 2004, p. 33).

Pensamos então que tentativas de relativizar a ciência por sua natural interdependência do contexto em que é produzida, de modo a vilipendiar suas impressionantes conquistas reduzindo-as a conjuntos de explicações temporalmente arbitrárias é, no mínimo, um viés de confirmação, onde parte de seu procedente ataque à objetividade acaba por se tornar uma caricatura da instituição que procura atacar. Isso já seria um problema per se (e mais adiante voltaremos a ele), mas somado aos movimentos anticientíficos exemplificados a seguir, torna-se uma perigosa combinação.

\section{Entrando (só um pouco) no Reino dos Nefelibatas}

Desde meados dos anos 1960, a Fundação Educacional James Randi oferecia um prêmio de um milhão de dólares para quem conseguisse demonstrar qualquer fenômeno paranormal em um ambiente cientificamente controlado. Depois de décadas de tentativas malsucedidas de centenas de candidatos interessados no prêmio, a oferta foi cancelada em 2015, pelo seu próprio fundador, James Randi, para que o dinheiro fosse usado em iniciativas mais construtivas, como bolsas de estudo em ciências (para quem ainda quiser pleitear a honraria, há diversas instituições que oferecem prêmio semelhante, como o Independent Investigations Group) (UNDERDOWN, 2012). Mágico canadense que dedicou a vida ao ilusionismo, Randi mostrou incessantemente que esta prática serve tão somente para divertir por meio do engano, de confundir nossas firmes convicções do que é real, e não para deliberadamente enganar as pessoas para proveito próprio, como repetidas vezes demonstrou. Para uma divertida e importante exposição de James Randi, ver a palestra disponível em Randi (2007). De conversas com os mortos a curas espirituais, Randi ataca diversas práticas pseudocientíficas, discutindo como essas são mais perigosas do que simplesmente ideias ingênuas de pessoas inconsequentes, quando não mal-intencionadas.

Um ponto que nos chama a atenção nas falas de Randi é a sugestão de que a educação científica é uma das vias onde esse tipo de prática crítica deveria ser incentivada.

\footnotetext{
'É um tanto pessimista imaginar que cientistas não possam concordar que conceitos e grandezas correlatas de diferentes teorias (como a massa, nas teorias de Newton e Einstein) podem ser relacionados ou mesmo ressignificados de modo mais abrangente.
} 
Usando como exemplo um desses movimentos anticientíficos, a saber, o movimento cultural antivacina, sugerimos que em se tratando de educação científica, temos que tratar a questão do ensinar diferentes pontos de vista (e supostamente deixar o aluno escolher em que acreditar) de modo mais responsável.

De modo algum pretendemos sugerir que a atividade científica seja detentora de uma verdade inquestionável, tampouco, relativo ao exemplo aqui escolhido, que a indústria farmacêutica opera apenas em função do bem comum. Mas cabe ressaltar que existe uma grande diferença entre posturas sobre as atividades humanas que não podem ser consideradas mutuamente procedentes. Se algumas alegações forem tidas por adequadas, outras precisam não o ser, em decorrência lógica. Se acreditarmos que os testes científicos duplo-cego na área da saúde, na avaliação da eficácia de uma vacina, por exemplo, têm nos dado um indicativo matematicamente confiável de eficácia, não poderemos tolerar acriticamente práticas que atuem no sentido inverso, defendendo que essas mesmas vacinas causam mais males do que benefícios. Isso não significa que devamos aceitar acriticamente os resultados desses testes, mas que nossas posições a respeito deveriam estar pautadas por avaliações bem informadas e objetivas dos dados disponíveis. Claro, não sugerimos que isso seja algo simples de ser feito. De modo geral, apenas chamamos atenção para que, tanto a dúvida pela dúvida, quanto a crença pela crença, são atitudes pouco racionais, e perigosas, no contexto da saúde pública. Como exemplo, ver a notícia vinculada pela BBC Brasil (SARAMPO..., 2019).

O excesso de relativização da prática e dos resultados da ciência pode desenvolver, como no caso do movimento antivacina, posturas onde os processos científicos são questionados e criticados em detrimento de práticas pseudocientíficas mortais. Como se não bastasse, acabam por atacar os críticos céticos de cientificistas, ou positivistas ${ }^{2}$.

Existem diversas pesquisas tratando dos impactos sociais gerados pelos movimentos anticiência. Seja discutindo a suposta influência de posições políticas na confiabilidade da ciência (HAMILTON, 2015; LEWANDOWSKY; OBERAUER, 2016; ROSENAU, 2012), ou sobre como a divulgação científica de má qualidade pode contribuir para esse processo (BROCKINGTON; MESQUITA, 2016), a maioria aponta para a necessidade de melhorias na educação científica. É irônico (se não trágico) que trabalhos em áreas científicas possam se tornar um 'fogo amigo':

Em 1998, no Reino Unido, o médico Andrew Wakefield e sua equipe divulgaram um relatório que abordava o fato de 12 crianças terem desenvolvido autismo após receberem a vacina MMR [caxumba, sarampo, rubéola]. A forma com que esses resultados foram noticiados fez com que muitos pais se recusassem a vacinar seus filhos, reduzindo a taxa de vacinação de $94 \%$ para $75 \%$ na Inglaterra (LEWANDOWSKY; OBERAUER, 2016, p. 31, tradução nossa).

Não sugerimos que o médico citado seja algum tipo de persona non grata na academia científica. Possíveis resultados discordantes com o conhecimento estabelecido têm seu valor para o desenvolvimento da ciência (podendo ser altamente relevantes), uma vez que a ciência se nutre de discussões embasadas, e quando todo mundo está concordando, pouco estamos aprendendo. O problema, como a citação sugere, é a maneira complexa como a informação circula na sociedade, com diversos meios de comunicação amalgamando seus interesses (e sua falta de expertise) às informações propaladas. Isso acaba produzindo fenômenos sociais

${ }^{2} Q u e$, diga-se, acabou se tornando um suposto ataque a quem valoriza resultados experimentais e admite que existem ideias melhores do que outras. 
que desencadeiam, além da hesitação de pais em vacinar seus filhos e o consequente retorno de doenças erradicadas, a sensação de que a atividade científica e seus representantes são o verdadeiro mal. Quando não vacinar seus filhos soa menos perigoso do que seguir as recomendações da saúde pública devidamente apoiada por bateladas de evidências, é sinal de que existe um problema sério de informação de qualidade, na sociedade ${ }^{3}$. Se houver qualquer ligação entre essas atitudes inconsequentes e o governo, como parece acontecer em alguns países, o perigo é ainda maior. "Quando a negação da ciência se torna política oficial do governo, o número de mortos pode chegar às centenas de milhares" (LEWANDOWSKY; OBERAUER, 2016, p. 218).

Podemos sugerir que fora justamente apelando para a autoridade do médico citado que essa notícia tomou robustez e fora disseminada, afinal se tratava de um relatório apresentado 'cientificamente'. Um problema sério decorrente é que, mesmo depois de o trabalho ser devidamente revisitado pela ciência, mostrando que o resultado divulgado não se sustentava, o fenômeno social da antivacina já estava gestado, e dificilmente capaz de ser abortado. Mesmo com a insistência de muitos médicos depois desse episódio, pesquisas recentes (KATA, 2012; SHELBY; ERNST, 2013; WARD, 2016) mostram como o movimento continua. ${ }^{4}$

Shelby e Ernst (2013) sugerem que a forma como médicos divulgaram a importância da vacinação causaram pouco ou nenhum efeito nos pais que agora decidiram não vacinar mais seus filhos. Sugerem ainda a possibilidade de utilizar os mesmos veículos - no caso, as redes sociais - dos movimentos antivacina para promover a discussão esclarecida da importância da vacinação. "Uma história compartilhada entre os pais, ou entre pai e provedor, às vezes pode ter mais impacto do que uma visita realizada [por órgãos de saúde pública]". (SHELBY; ERNST, 2013, p. 1799, tradução nossa).

Outros autores advogam que, além da raiz política e das pesquisas duvidosas, esses movimentos nascem devido a um culto à pós-verdade, que nada mais é do que o relativismo que estamos discutindo (HIGGINS, 2016; LUBCHENCO, 2017; WOLPERT, 1988). O biólogo britânico Lewis Wolpert, membro da Royal Society, já na década de 1980 chamava atenção para dois pontos que julgamos muito importantes: primeiro, de que ameaças à ciência vem menos de ativistas paranormais, do que o autor chamou de "sociologistas da ciência"; e, segundo, lembrando sutilmente do chamado "problema da demarcação", quando enfatiza que "[...] só porque não há uma maneira clara de demarcar a ciência da não-ciência, não devemos nos impedir de reconhecer o absurdo quando o vemos" (WOLPERT, 1988, p. 1, tradução nossa). Cabe destacar que não sugerimos (e não é o que Wolpert sugere também), que o problema seja os sociólogos da ciência ou a própria sociologia da ciência. Consideramos a importância das discussões sociológicas sobre a atividade científica algo indiscutível.

\footnotetext{
${ }^{3}$ Admitimos também outra possibilidade, possivelmente concomitante: existe, sim, informação de qualidade circulando. Mas por razões socialmente complexas sempre existe uma parcela da sociedade imune a essas informações ou, simplesmente, alienada em relação às ideias opostas às suas. Ou seja, o que leva um sujeito a crer ou não crer é reflexo de uma psicologia não necessariamente sensível às argumentações científicas. Nossa questão principal a esse respeito é que, a despeito das complexidades várias de aceitação de uma ou outra linha argumentativa, a educação científica e a divulgação de qualidade devem sempre observar um interesse primário de promoção da sanidade social. Em suma, as complexidades psicológicas de aceitação não devem ser um obstáculo à educação responsável.

'É assim que a 'imagem da santa' gera um resultado midiático que não é desfeito depois de ser explicado por algum pesquisador estraga-prazeres. A quebra das leis naturais é interessante para a audiência. A explicação, aparentemente muito menos.
} 
No entanto, o que o autor e nós chamamos a atenção é para o sociologismo exacerbado, também denunciado pelo físico e filósofo Mario Bunge (BUNGE, 1991), na interpretação dos processos e resultados da atividade científica. Ilustraremos esse ponto na seção seguinte.

Sobre o segundo ponto, é claro que a atividade científica é uma atividade humana complexa que dificulta uma demarcação peremptória sobre o que é ou não científico. Mas diante dessa complexidade, algumas sugestões parecem querem advogar contra qualquer tentativa de se hierarquizar os conhecimentos como científicos ou não-científicos, e isso é absurdo. Que Feyerabend (1977) tenha ilustrado o ensino de magia nas escolas como um artifício argumentativo (extremo) é uma coisa, defender que de fato devemos ensinar magia (ou astrologia, tratamentos holísticos, charlatanismo quântico, curas espirituais e todo o tipo de esoterismo moderno) é simplesmente irresponsável, desarrazoado e mesmo risível.

O movimento antivacina é apenas um exemplo do que consideramos um movimento anticientífico. Poderíamos fazer a mesma argumentação com os chamados 'terraplanistas' (SILVEIRA, 2017), ou os defensores do ensino do 'design inteligente' (criacionismo religioso disfarçado de ciência) nas escolas como uma 'teoria alternativa' à evolução das espécies, ou, ainda, às teorias que negam a ida do homem à Lua, em 1969. Citando um breve exemplo, um editorial do periódico científico Nature Cell Biology aponta que "[...] esforços para introduzir o criacionismo e teorias pseudocientíficas, como o design inteligente, nos currículos de ensino dos EUA estão bem documentados, assim como o ceticismo do público americano em relação à evolução" (THE CHALLENGE..., 2018, p. 1231, tradução nossa). Mas isso é lá com eles, e aqui no Brasil não sofremos deste mal, certo? Em 2012, um deputado federal apresentou à Câmara dos Deputados um Projeto de Lei que tornaria obrigatório o ensino do criacionismo como alternativa científica ao que o deputado chama de evolucionismo. Não, a ignorância quanto aos processos assintoticamente objetivos da ciência não estão (nunca estiveram) muito longe.

Outro breve exemplo de crendice disfarçada de ciência é a prática da homeopatia, que advoga o efeito clínico de compostos diluídos para além do limite de Avogadro, ou seja, de modo a não mais existir moléculas do princípio ativo na solução, o que é "[...] um conceito absurdo que nega o progresso da física e da química" (BAUM; ERNST, 2009, p. 973, tradução nossa). Apesar de alguns médicos prescreverem medicamentos homeopáticos, a pesquisa médica compromissada com evidências mostra que isso é um equívoco, porque simplesmente não existem resultados contundentes a favor desta prática, nem mesmo uma vaga evidência de que devamos manter a mente aberta (BARRETT; TYLER, 1995, BAUM; ERNST, 2009). Os resultados confusos e amalgamados com pensamento desejoso produzem toda uma literatura disfarçada de conhecimento científico genuíno, evocando mesmo a Mecânica Quântica de modos absolutamente às margens da produção séria nesta área. Em uma publicação correlata, encontramos a sugestão de que os supostos efeitos das "diluições homeopáticas ultramoleculares" estariam relacionados ao "[...] entrelaçamento quântico macroscópico" (FISHER, 2007, p. 141, tradução nossa). Claro, não podiam deixar a Mecânica Quântica de fora. Atualmente, é um dos rótulos mais explorados pela pseudociência (CRUZ; CRUZ, 2009), com resultados também perniciosos à saúde pública e à sanidade social como um todo.

Como lembrado em The genious of Charles Darwin (THE GENIUS..., 2008) "aviões voam. Tapetes mágicos e vassouras não". Pensamos que não é necessário esperar pelo momento em que panaceias sejam ofertadas generalizadamente nos hospitais, colocando várias vidas em risco, para percebermos que divulgar e ensinar ciência está muito além de simplesmente 
promover 'diferentes pontos de vista'. Como Gerald Holton sugeriu, "[...] a educação científica não é apenas uma questão de democracia, mas de sanidade social" (OLIVEIRA; FREIRE, 2006, p. 322).

\section{A Materialidade das Teorias Científicas}

Nossas teorias não nos são dadas diretamente pela natureza, claro. Mas também não tiramos nossas teorias da manga, ou da cartola. O físico Werner Heisenberg, um dos criadores da Mecânica Quântica, já enfatizava que a ciência está entre a natureza e o homem (BORN et al., 2000). Teorias científicas são livres criações da mente humana, mas a expressão "livres criações" guarda aqui significados bastante distintos do que se costuma imaginar. Bunge (1985, p. 53), por exemplo, nem sequer concordaria com isso, enfatizando que as teorias científicas se constroem por meio de limitações impostas pela realidade. Para além do que os relativistas advogam, as teorias científicas ou, melhor, seus proponentes, possuem uma materialidade ontológica ${ }^{5}$ sem a qual qualquer perscrutação científica perderia seu propósito de apreender a natureza. E isso delimita o que poderíamos nos referir como 'livres criações'. Pois enquanto nossa imaginação e criatividade são, naturalmente, os únicos limitantes de nossas produções intelectuais científicas, o que distingue o resultado efetivo dessas produções de qualquer outra composição da mente humana é sua relação com uma realidade objetiva que não admite 'qualquer criação': no fim há de se trabalhar com borracha e lixeira, ou seja, constructos mentais devem ser revisitados, retificados, ratificados, ou mesmo abandonados quando o contexto o exige.

Por mais intrincado que seja o processo de gênese de uma teoria, onde tomam forma diversos elementos subjetivos por parte do cientista, pensamos ser contraproducente qualquer tentativa de negar, em princípio, a objetividade do fenômeno (o que faz o relativismo radical). É claro que a evidência de um fenômeno pode ser percebida como tal por um cientista ou grupo de cientistas, e não o ser por outros. Por exemplo, sabemos que existe uma radiação que nos chega de todas as direções, provinda do espaço, com uma temperatura de cerca de 2,7 K. Esse ruído cósmico de fundo, na faixa do microondas no espectro eletromagnético, é considerado uma evidência a favor do modelo padrão da cosmologia que lida com um universo em expansão (popularmente conhecido como Teoria do Big Bang), uma vez que foi previsto no contexto das pesquisas que lidam com os instantes iniciais do nosso universo observável (SMOOT; DAVIDSON, 1995). Contudo, existem pesquisadores que enxergam nesse mesmo dado observacional um indicativo da simples temperatura média do universo (NEVES, 2000), sem relação necessária com um universo em expansão, conforme defendido pelos cosmólogos do modelo padrão. Ou seja, um mesmo dado observacional pode ser utilizado como evidência de teorias distintas, apesar de o modelo padrão da cosmologia estar em melhores condições, neste exemplo. As predições provindas desta teoria são mais sofisticadas, levando inclusive a uma variação na temperatura do ruído cósmico de fundo, efetivamente constatada na década de 1990 (SMOOT; DAVIDSON, 1995).

Naturalmente, estes embates científicos (muito benéficos para a ciência) podem levar a anos de genuína controvérsia acadêmica, mas é importante enfatizar aqui que os pesquisadores de ambas as linhas de pesquisa não estão colocando em dúvida a objetividade da evidência, se a radiação existe ou não. Ela 'está ali', e qualquer antena calibrada para sua

${ }^{5}$ Por materialidade ontológica entendemos uma posição realista diante da natureza, onde sua existência material é tomada como factual por princípio. 
detecção, em qualquer parte do mundo, operada por qualquer pesquisador, recepta as mesmas características. Uma coisa é advogar a favor da impossibilidade científica de operar com verdades peremptórias (o que também fazemos), outra muito diferente é usar (e aceitar) a realidade de um dado como aporte na argumentação do relativismo científico, o que é, no mínimo, logicamente incoerente. $\mathrm{E}$, se se aceita a realidade de um dado (como a radiação eletromagnética, neste exemplo), aceita-se por decorrência que podemos concordar sobre a materialidade dos fenômenos, e consequentemente que uma teoria possa vir a ser objetivamente melhor do que outra ao lidar com essa materialidade.

Uma das características mais frontalmente definidoras da ontologia realista da atividade científica é justamente sua relação com a experimentação. Não se espera que um experimento nos mostre algo da natureza se não se admite sua objetividade assintótica, e as tentativas de relativizar a atividade científica têm falhado copiosamente em justificar o progresso da ciência enquanto ferramenta de predição, resultado de uma correlação fantástica com a natureza. É claro que existem casos onde os consensos são mais frágeis, o que deveria ser visto como resultado da vicissitude de perscrutação científica de campos em desenvolvimento. Naturalmente as relações estabelecidas entre teoria e experimentação são complexas, muitas vezes levando a pontos de vista distintos, por vezes frontais, mesmo se olhando para os mesmos dados, conforme vimos acima. Mas não deveríamos levar incongruências existentes neste processo de explicação e teste ao patamar de regra geral, quando é o caso discordante que deve ser analisado.

No século XIX, James Clerk Maxwell sintetizou o eletromagnetismo em um conjunto de equações (as equações de Maxwell) que permitiu a previsão das ondas eletromagnéticas. Estas foram encontradas alguns anos depois, por dois cientistas de modo independente: Heinrich Hertz (cujo sobrenome hoje batiza a unidade de medida de frequência), e Oliver Lodge. Cada vez que atendemos o celular, ou mesmo mudamos o canal da TV, estamos testemunhando a realidade das ondas eletromagnéticas a literalmente colidir conosco e nossos equipamentos, em uma relação com a natureza que está em um nível de realidade igual a nossa própria. A menos que sejamos solipsistas, é difícil aceitar uma invencionice por parte dos cientistas relativa à materialidade deste fenômeno que, diferentemente de uma realidade imediata de se dar uma topada em uma pedra, por exemplo, nunca tinha sido conscientemente percebido na natureza. Foi necessária uma previsão teórica para que pesquisadores buscassem e constatassem sua existência, em uma relação com a natureza bastante diferente de uma arbitrariedade constituída socialmente.

Caso bastante semelhante se deu com a descoberta do planeta Netuno, previsto usando-se a Gravitação Universal newtoniana. Irregularidades na órbita de Urano levaram os astrônomos a procurar um novo planeta no sistema solar (SILVEIRA, 1996), nunca antes visto (ou, se o foi, nunca relatado como tal). Nenhum realista duvida que Netuno sempre 'esteve lá' (pelos menos nas escalas de tempo de existência do sistema solar), mas foi necessário que uma teoria guiasse nossa atenção até ele. O mesmo vale para a descoberta de que a luz é encurvada pela gravidade quantitativamente segundo as previsões de Einstein, com sua Relatividade Geral: não duvidamos que a luz sempre fez isso. Mais uma vez, uma teoria nos avisou dessa possibilidade, para efetivamente constatarmos esse fenômeno. Essa lista é fascinante: raio laser, buracos negros, ondas gravitacionais, e praticamente todas as partículas subatômicas foram resultado de predições teóricas, o que mostra, ainda, como a imagem de uma ciência que apenas 'descobre' coisas e inventa explicações para essas é bastante limitada. 
Essa capacidade de promover predições, mais tarde constatadas, foi (e vem sendo) sistematicamente ignorada pelas exegeses relativistas e sociologistas (BUNGE, 1991), que costumam se concentrar no seu dedo quando você os aponta uma estrela. É claro que a sociedade afeta o rumo das teorias e a própria atividade científica, juntamente com seus resultados. Mas de modo distinto do que costuma ser propalado. Para ilustrar essa questão, gostaríamos de repetir uma breve história, originada no livro The Gordian Knot, de 1998, sobre história da comunicação. Os ônibus espaciais, hoje aposentados (você pode ver um bem de perto no complexo de visitação do Kennedy Space Center, na Flórida), eram produzidos com partes provindas de indústrias de diferentes estados americanos. Algumas dessas partes, como os tanques de combustível, tiveram que ser fabricados com dimensões tais que pudessem ser transportados pelos trens americanos, por sua vez de dimensões determinadas pela distância entre os trilhos (cerca de 1,40 m). Essa distância, por sua vez, é resultado das medidas do eixo das carroças usadas antes das ferrovias, que por um tempo foram produzidas pelas mesmas empresas. O eixo das carroças tinha essa dimensão para que as mesmas pudessem aproveitar, como estrada, as vias europeias medievais, por sua vez determinadas em seu passado pelas antigas bigas romanas. Finalmente, as antigas bigas romanas tinham dimensões adequadas para se encaixarem nos traseiros dos cavalos, usados então como tração. Uma conclusão possível, seria então a de que o traseiro de um cavalo na Roma antiga determinou as dimensões do ônibus espacial da NASA! Mas determinou mesmo?

Se por alguma razão, em algum momento, as ferrovias fossem inutilizadas, ou se decidisse por outro tipo de transporte, as dimensões das peças também poderiam ser alteradas, conforme as necessidades de transporte. Ou seja, se não fosse devido ao trem, seria devido a outro veículo. $E$ uma vez que os engenheiros e cientistas da NASA conhecem um pouco de mecânica dos fluidos, a eficiência aerodinâmica do ônibus espacial certamente poderia ser obtida com variações nos parâmetros de suas peças, de modo que, de um modo ou de outro, o ônibus espacial seria produzido e utilizado com sucesso. Portanto, naturalmente a ciência é afetada pelo seu entorno, mas não é determinada necessariamente por esse! A insistência em sociologizar a produção do conhecimento científico de modo peremptório, por alguns professores e pesquisadores, acaba por privilegiar apenas uma metade da lâmina. Em um contexto educacional, pensamos que isso é tão reprochável quanto passar uma imagem empirista ingênua da atividade científica.

Além das previsões possibilitadas pelas teorias, os resultados obtidos de forma independente, por diferentes cientistas, por vezes em diferentes épocas, atestam a materialidade objetiva da ciência. Por exemplo, na primeira metade do século XX a Física Quântica encontrou sua sistematização matemática por duas frentes: Erwin Schrödinger, com sua equação de onda, e Werner Heisenberg, com suas matrizes (SEGRÈ, 1987). Mais tarde foi mostrado que essas duas formulações são matematicamente equivalentes, e geram os mesmos resultados. Se considerarmos as teorias científicas como construções sociais arbitrárias, como explicar esse feito? Perguntamo-nos sinceramente se os relativistas genuinamente conhecem os resultados da Quântica, com muitas propriedades sendo previstas (e posteriormente constatadas) quantitativamente com muitas casas decimais de precisão.

A queda independente da massa, por Galileu e Stevin, a lei da refração ótica entre dois meios de propagação, por Snell e Descartes, a indução eletromagnética, por Faraday e Henry, a idealização do primeiro capacitor, por Kleist e Musschenbroek, a previsão do planeta Netuno, 
por Adams e Le Verrier, a lei da fotoequivalência, por Einstein e Stark, a chamada relação de Einstein, usada no contexto da explicação do movimento browniano, por Sutherland, Einstein e Smoluchowski, a dinâmica de captura de gás por buracos negros, por Salpeter e Zel'dovich, a eletrodinâmica quântica, por Feynman, Schwinger e Tomonaga, a previsão do mecanismo de atribuição de massa a certa classe de partículas (hoje conhecido por mecanismo de Higgs), por Peter Higgs e François Englert ${ }^{6}$, e inúmeros outros casos de obtenção de resultados equivalentes e independentes ocorreram e ocorrem na ciência. Muitos prêmios Nobel são outorgados a mais de um cientista justamente por isso.

Com isso gostaríamos de relativizar as relativizações que frequentemente vêm sendo sugeridas no ensino. Se não para o valor intrínseco do argumento racional com lastro em evidências, pela necessidade do pluralismo de visões no ensino. No caso, se os relativistas podem se fazer presentes (como pensamos que efetivamente podem) no processo de ensino e aprendizagem de conceitos científicos, pensamos que também temos a prerrogativa (e, por enquanto, o direito) de nos fazermos presentes.

\section{Conclusão}

Pelo exposto, ousamos sugerir que um relativista é uma pessoa perniciosa à educação e de pouca ou nenhuma contribuição à noosfera. Um relativista não admite a possibilidade de vacinas funcionarem objetivamente porque foram produzidas com base em testes duplocego cujos resultados frios, estatísticos, correlacionam-se com a realidade pelos meios apresentados pelas ciências biológicas (do contrário não são relativistas, ao relevarem situações de alta correlação empírica). Ao negarem a objetividade de um teste duplo-cego (passível de erros, porém de ordem bastante distinta da invencionice), por exemplo, ao não conhecerem (ou ignorarem) os resultados do efeito placebo e como eles se relacionam quantitativamente com as conclusões da pesquisa, ao endossarem, justamente pelo mesmo tipo de desconhecimento, práticas pseudocientíficas, os relativistas (entre eles alguns professores) podem tornar o meio escolar o oposto da emancipação que paradoxalmente desejam aos educandos. O que ganha um aluno ao ser privado de uma apresentação da objetividade da ciência, a não ser estar na rota de uma bala de canhão ${ }^{7}$ atirada justamente pela atividade cuja eficácia é relativizada? É um verdadeiro contrassenso.

A complexidade da atividade científica pode e deve ser enfrentada na sequência, mostrando toda a intrincada teia de ideias que buscam uma compreensão dos processos de obtenção de conhecimento científico. Não negamos nem mesmo que a ciência seja atacada enquanto uma panaceia e composta de um método científico onipotente (que simplesmente não existe). As complexidades do terreno epistemológico são patentes, mas focar exclusivamente neste tipo de questão para educandos que ainda nem foram expostos aos impressionantes resultados da ciência e suas metodologias assintoticamente críticas de perscrutação é, usando a máxima, jogar fora a água suja da banheira com o bebê junto. A liberdade emancipatória nos moldes feyerabendianos de ensinar magia junto com ciência só se mostraria construtiva se ao aluno fosse dado todos os instrumentos de decisão. E duvidamos sinceramente de que isso um dia já foi feito nas escolas.

\footnotetext{
${ }^{6}$ Outros físicos chegaram no mesmo mecanismo teórico: Robert Brout, Gerald Guralnik, Carl Hagen e Tom Kibble, o que é mais um exemplo do incrível poder heurístico de uma teoria, e como pesquisadores de modo independente podem obter resultados correlatos que atestam frontalmente a materialidade das teorias e a ontologia realista da atividade científica.

${ }^{7}$ Representando metaforicamente todos os efeitos que a ciência e a tecnologia exercem sobre sua vida.
} 
Sugerimos que o ensino de ciências deva se preocupar cada vez mais com o contexto de produção do conhecimento científico. Isso mostra o caráter humano do desenvolvimento da ciência, com o cientista sendo muito mais um detetive sem um rumo definido, que segue pistas, que erra, que refaz, que duvida, que se apega, do que propriamente um seguidor de uma receita infalível que leva ao sucesso explicativo. Mas ao invés de insistir apenas nesses aspectos, esperamos que os resultados de explícita correlação com a natureza sejam também oferecidos aos alunos, conforme os exemplos apresentados. Isso pode possibilitar que o aluno perceba como geralmente as construções intelectuais da atividade científica, mesmo com todas as vicissitudes humanas do cientista, estão sinceramente compromissadas com evidências materiais bastante contundentes.

Para que isso seja possível, naturalmente o professor de ciências precisa transitar entre os diferentes âmbitos de sua disciplina: conteúdo e processo. Mas infelizmente temos constatado, com relutante descrença, a quantidade de colegas (normalmente fora das áreas das ciências naturais, mas não raro de dentro dessas) que estão transitando por vias bem diferentes. De um deles, ouvimos que o homem nunca foi à Lua. De outro, que vacinas são parte de conspirações da indústria farmacêutica ${ }^{8}$. De mais outro, que a ciência não passa de relações de poder (do que concordaríamos prontamente se a afirmação fosse de que na ciência existem relações de poder). E de mais um, que bastões magnéticos colocados na água curam diversas doenças, e a Mecânica Quântica prova isso. Esse tipo de folclore pseudocientífico só tem a ganhar com a insistência sistemática em não se trabalhar com as evidências, no ensino de ciências, em abordagens pautadas pelo realismo cientifico.

Aos professores que compactuam com nossas preocupações, enfatizamos que, além dos resultados da ciência, precisamos falar mais em processos e evidências.

\section{Referências}

BARRETT, S.; TYLER, V. E. Why pharmacists should not sell homeopathic remedies. American Journal of Health-System Pharmacy, Bethesda, v. 52, n. 9, p. 1004-1006, 1995. DOI: https://doi.org/10.1093/ ajhp/52.9.1004

BAUM, M.; ERNST, E. Should we maintain an open mind about homeopathy? The American Journal of Medicine, New York, v. 122, n. 11, p. 973-974, 2009. DOI: https://doi.org/10.1016/j. amjmed.2009.03.038

BORN, M. et al. Problemas da física moderna. São Paulo: Perspectiva, 2000.

BROCKINGTON, G.; MESQUITA, L. As consequências da má divulgação científica. Revista de Biologia, São Paulo, v. 15, n. 1, 2016. DOI: https://doi.org/10.7594/revbio.15.01.03

BUNGE, M. Una caricatura de la ciencia: la novisima sociologia de la ciencia. Interciencia, Caracas, v.16, n. 2, p. 69-77, 1991.

BUNGE, M. Seudociencia e ideologia. Madrid: Alianza, 1985.

THE CHALLENGE of the post-truth era. Nature Cell Biology, London, v. 20, p. 1231, 2018. DOI: https:// doi.org/10.1038/s41556-018-0231-z

${ }^{8}$ Não excluímos a possibilidade de que existam condutas neste sentido. O problema está na generalização infundada. 
CRUZ, F. F. S.; CRUZ, S. M. S. C. S. Pode o ambiente cultural e social definir o conteúdo escolar de física: o caso da mecânica quântica. In: ENCONTRO NACIONAL DE PESQUISA EM EDUCAÇÃO EM CIÊNCIAS, 7., 2009, Florianópolis. Atas [...]. Disponível em: http://posgrad.fae.ufmg.br/posgrad/ viienpec/pdfs/1581.pdf. Acesso em: 3 abr. 2020.

DELIZOICOV, D.; CASTILHO, N.; CUTOLO, L. R. A.; DA ROS, M. A.; LIMA, A. M. C. Sociogênese do conhecimento e pesquisa em ensino: contribuições a partir do referencial fleckiano. Caderno Brasileiro de Ensino de Física, Florianópolis, v.19, n. esp., p. 52-69, jun. 2002. Disponível em: https:// periodicos.ufsc.br/index.php/fisica/article/view/10054. Acesso em 20 abr. 2020.

FERNÁNDEZ, I.; GIL-PÉREZ, D.; CARRASCOSA, J.; CACHAPUZ, A.; PRAIA, J. Visiones deformadas de la ciencia transmitidas por la enseñanza. Enseñanza de las Ciencias, Barcelona, v. 20, n. 3, p. 477-488, 2002. Disponível em: https://ddd.uab.cat/record/1581. Acesso em: 6 abr. 2020.

FEYERABEND, P. K. Contra o método. Rio de Janeiro: Francisco Alves, 1977.

FISHER, P. The memory of water: a scientific heresy? Homeopathy, Stuttgart, v. 96, n. 3, p. 141-142, 2007. DOI: https://doi.org/10.1016/j.homp.2007.05.008

THE GENIUS of Charles Darwin. Direção: Russell Barnes. Intérpretes: Daniel C. Dennett, Richard Dawkins. Roteiro: Richard Dawkins. London: Channel 4, 2008. 106 min, son., color.

HAMILTON, L. C. Conservative and liberal views of science: does trust depend on topic? Carsey Research: regional issue brief, Durham, n. 45, p. 1-10, 2015. Disponível em: https://scholars.unh.edu/ cgi/viewcontent.cgi?article=1251\&context=carsey. Acesso em: 6 abr. 2020.

HIGGINS, K. Post-truth: a guide for the perplexed. Nature, London, v. 540, p. 9, 1 dec, 2016. Disponível em: https://www.nature.com/news/post-truth-a-guide-for-the-perplexed-1.21054. Acesso em: 6 abr. 2020.

KUHN, T. S. A função do dogma na investigação científica. In: A CRÍTICA da ciência. Rio de Janeiro: Zahar, 1979. p. 52-79.

KUHN, T. S. A estrutura das revoluções científicas. São Paulo: Perspectiva, 1970.

KATA, A. Anti-vaccine activists, web 2.0, and the postmodern paradigm: an overview of tactics and tropes used online by the anti-vaccination movement. Vaccine, Amsterdam, v. 30, n. 25, p. 37783789, 2012. DOI: https://doi.org/10.1016/j.vaccine.2011.11.112

LEWANDOWSKY, S.; OBERAUER, K. Motivated rejection of science. Current Directions in Psychological Science, Washington, v. 25, n. 4, p. 217-222, 2016. DOI: https://doi.org/10.1177/0963721416654436

LUBCHENCO, J. Environmental science in a post-truth world. Frontiers in Ecology and the Environment, Hoboken, v. 15, n. 1, p. 3, 2017. DOI: https://doi.org/10.1002/fee.1454

NEVES, M. C. D. A questão controversa da cosmologia moderna: Hubble o infinito parte 1. Caderno Brasileiro de Ensino de Física, Florianópolis, v. 17, n. 2, p. 189-204, 2000. Disponível em: https:// periodicos.ufsc.br/index.php/fisica/article/view/6772/6241. Acesso em: 6 abr. 2020.

OLIVEIRA, B. J.; FREIRE JR., O. Uma conversa com Gerald Holton. Caderno Brasileiro de Ensino de Física, Florianópolis, v. 23, n. 3, p. 315-328, 2006. Disponível em: https://periodicos.ufsc.br/index.php/ fisica/article/view/5810/5800. Acesso em: 6 abr. 2020.

RANDI, J. James Randi e seu feroz combate à fraude psíquica. TED: ideas worth spreading. 2007. Disponível em: https://www.ted.com/talks/james_randi_homeopathy_quackery_and_ fraud?language=pt-BR. Acesso em: 2 fev. 2019. 
RENN, J. A física clássica de cabeça para baixo: como Einstein descobriu a teoria da relatividade especial. Revista Brasileira de Ensino de Física, São Paulo, v. 27, n. 1, p. 27-36, 2004. DOI: https://doi. org/10.1590/S1806-11172005000100004

ROSENAU, J. Science denial: a guide for scientists. Trends in Microbiology, Cambridge, v. 20, n. 12, p. 567-569, 2012. DOI: https://doi.org/10.1016/j.tim.2012.10.002

SARAMPO: O menino francês não vacinado que reintroduziu a doença na Costa Rica. BBC Brasil, 28 fev. 2019. Disponível em: https://www.bbc.com/portuguese/geral-47408849. Acesso em: 28 fev. 2019.

SEGRÈ, E. Dos raios X aos quarks: físicos modernos e suas descobertas. Brasília: Universidade de Brasília, 1987.

SHELBY, A.; ERNST, K. Story and science: how providers and parents can utilize storytelling to combat anti-vaccine misinformation. Human Vaccines \& Immunotherapeutics, Austin, v. 9, n. 8, p. 1795-1801, 2013. DOI: https://doi.org/10.4161/hv.24828

SILVEIRA, F. L. A metodologia dos programas de pesquisa: a epistemologia de Imre Lakatos. Caderno Catarinense de Ensino de Física, Florianópolis, v. 13, n. 3, p. 219-230, 1996. Disponível em: https:// periodicos.ufsc.br/index.php/fisica/article/view/7047. Acesso em: 28 fev. 2019.

SILVEIRA, F. L. Sobre o formato da Terra. Física na Escola, São Paulo, v. 15, n. 2, p.4-14, 2017. Disponível em: http://www1.fisica.org.br/fne/phocadownload/Vol15-Num2/a02-low.pdf. Acesso em: 6 abr. 2020.

SMOOT, G. F.; DAVIDSON, K. Dobras no tempo. Rio de Janeiro: Rocco, 1995.

UNDERDOWN, J. The independent investigations group. 2012. Disponível em: https://www.iigwest. com/iigawards/. Acesso em: 5 fev. 2019.

WARD, J. K. Rethinking the antivaccine movement concept: a case study of public criticism of the swine flu vaccine's safety in France. Social Science \& Medicine, Amsterdam, v. 159, p. 48-57, 2016. DOI: https://doi.org/10.1016/j.socscimed.2016.05.003

WOLPERT, L. Pseudoscience and antiscience. Nature, London, v. 334, p. 114, 14 jul. 1988. DOI: https://doi.org/10.1038/334114a0 